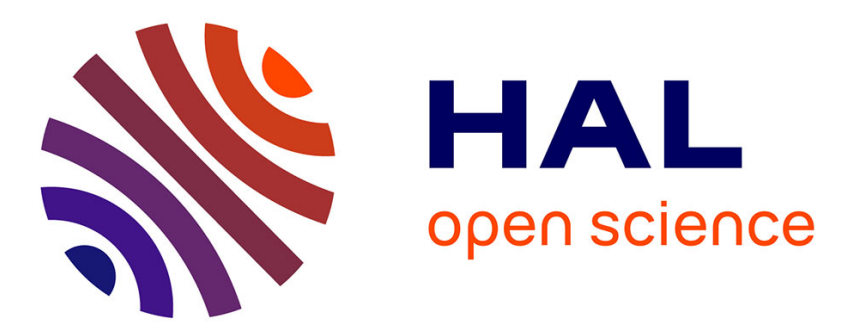

\title{
MOLECULAR PARAMETERS OF THE ND3 GROUP IN THE LITHIUM-TETRAAMMINE COMPOUND Li (ND3)4 USING LARGE ANGLE NEUTRON SCATTERING (LANS)
}

\author{
F. Leclercq, P. Damay, P. Chieux
}

\section{To cite this version:}

F. Leclercq, P. Damay, P. Chieux. MOLECUlAR PARAMETERS OF THE ND3 GROUP IN THE LITHIUM-TETRAAMMINE COMPOUND Li (ND3)4 USING LARGE ANGLE NEUTRON SCATTERING (LANS). Journal de Physique IV Proceedings, 1991, 01 (C5), pp.C5-357-C5-363. 10.1051/jp4:1991542 . jpa-00250669

HAL Id: jpa-00250669 https://hal.science/jpa-00250669

Submitted on 1 Jan 1991

HAL is a multi-disciplinary open access archive for the deposit and dissemination of scientific research documents, whether they are published or not. The documents may come from teaching and research institutions in France or abroad, or from public or private research centers.
L'archive ouverte pluridisciplinaire HAL, est destinée au dépôt et à la diffusion de documents scientifiques de niveau recherche, publiés ou non, émanant des établissements d'enseignement et de recherche français ou étrangers, des laboratoires publics ou privés. 


\title{
MOLECULAR PARAMETERS OF THE ND 3 GROUP IN THE LITHIUM-TETRAAMMINE COMPOUND $\mathrm{Li}\left(\mathrm{ND}_{3}\right)_{4}$ USING LARGE ANGLE NEUTRON SCATTERING (LANS)
}

\author{
F. LECLERCQ, P. DAMAY and P. CHIEUX* \\ Laboratoire de Chimie-Physique, CNRS at HEI, 13 rue de Toul, F-59046 Lille cedex, France \\ *Institut Laue-Langevin, 156X, F-38042 Grenoble cedex, France
}

\begin{abstract}
It has already been shown that the molecular parameters of small rigid molecules as ND3 could be determined with a high accuracy from the analysis of the diffuse scattering measured from a Large Angle Neutron Scattering experiment (LANS) /1/.

The same type of experiment has been carried out on the molecular metal Li(ND3) 4 ; the ND3 molecular parameters are more difficult to extract than for the $\mathrm{Ca}\left(\mathrm{ND}_{3}\right)_{6}$ compound or the solid pure ammonia since Bragg peaks are still visible for momentum transfer up to $13 \AA^{-1}$. Nevertheless the usual parameter ND $=1.02 \AA$ and $\widehat{D N D} \sim 103$ degrees are well characterized in the lithium ammonia compound.
\end{abstract}

\section{Résumé}

L'analyse de la diffusion diffuse mesurée par diffraction de neutrons aux grands angles (LANS) permet de mesurer avec beaucoup de précision les paramètres moléculaires de petites molécules rigides en phase liquide ou solide $/ 1 /$.

Le même type d'expérience a été fait sur le métal moléculaire Li(ND3)4; l'analyse des données est plus compliquée que dans le cas du composé calcium-hexaammine car des pics de Bragg sont présents jusqu'à des moments de transfert de $13 \AA^{-1}$. Cependant les paramètres classiques du groupement ammoniac $\mathrm{ND}=1.02 \AA$ et $\widehat{\mathrm{DND}} \sim 103$ degrés sont bien caractérisés dans le composé lithium-ammoniac.

\section{I - Introduction}

The use of Xray diffraction at large momentum transfer $Q=4 \pi / \lambda \sin \theta$ is limited by the form factor of each element which falls off rapidly as the angle increases. Even for small ions, the scattered intensity is lowered by a factor of 5 at $Q=5 \AA^{-1}$. Since neutrons are scattered by nuclei, the scattering cross section does not depend on the angle and it is possible to investigate large momentum transfer if a neutron beam of short wavelength is used.

In a perfect powder crystal, all the scattered intensity accumulates in Bragg peaks at low values of the momentum transfer. Disorder induced by defects, temperature effect or even zero point motion breaks the 
interference condition; the intensity of Bragg peaks is thus decreasing and a diffuse background, more or less structured, shows up. The peak attenuation due to disorder is to the first order a function of $\mathrm{Q}^{2}$. At very large momentum transfer any interference and local correlation ultimately disappear and only a flat background whose the intensity is proportional to the density is observed; indeed at a level of a thousandth of an angstrom as probed at very large momentum transfer any solid appears as completely disordered.

In molecular crystal, small molecules are the more rigid edifices, the vibrational energy being of the order of $0.1-0.5 \mathrm{eV}$. The Debye-Waller factor, which is a function of the inverse of the bond strength, is small and intramolecular correlations may still be observed at large momentum transfer (10 to $25 \AA^{-1}$ ). It is thus possible to determine with a high accuracy the molecular parameters of small rigid molecules in crystals, amorphous solids or liquid using the technique of Large Angle Neutrons Scattering (LANS).

The molecular parameters of the $\mathrm{ND}_{3}$ group have already been determined by this method in pure solid and liquid $\mathrm{ND}_{3}$ as well as in the metallic compound $\mathrm{Ca}\left(\mathrm{ND}_{3}\right)_{6} / 1 /$. We report here new results obtained for the deuterated Lithium-Tetraammine Compound $\mathrm{Li}\left(\mathrm{ND}_{3}\right)_{4}$. Part II reports the sample preparation and the experimental set-up. The formalism and the different steps of the data processing are briefly exposed in part III. The resuits are then reported and discussed in part IV.

\section{II - Samples and Experimental set-up}

The neutron diffraction experiments were performed on the D4B diffractometer at the Institut LaueLangevin (Grenoble-France). The samples were prepared in quartz tubing $8 \mathrm{~mm}$ inner diameter. $\mathrm{ND}_{3}$ with an isotopic purity of $99.75 \%$ was purchased from the Centre d'Energie Atomique (Saclay - France). The isotope ${ }^{7} \mathrm{Li}$ isotope was obtained from Oak Ridge. An empty quartz cell was also used in order to subtract the signal observed from the container. The ${ }^{7} \mathrm{Li}-\mathrm{ND}_{3}$ sample was prepared on the usual way $/ 1 / ; a$ composition of 19.9 mole per cent metal was determined by gravimmetry of the metal and gas volumetry of the ammonia.

The wavelength $\lambda$ of the monochromatic neutron beam was calibrated as $0.5002 \AA$ using a nickel sample; this wavelength allowed to reach a maximum $Q$ value of $23.5 \AA^{-1}(Q=4 \pi / \lambda \sin \theta, 2 \theta$ the diffraction angle). The intensities were measured using two multidetectors ( ${ }^{3} \mathrm{He}$ ) placed at $1.50 \mathrm{~m}$ and $0.75 \mathrm{~m}$ from the sample; they cover respectively the ranges $1.68-64.78^{\circ}$ and $46.4-131.4^{\circ}$. The raw data analysis, correction for container and self-absorption, were made using a conventional method. Inelastic, multiple scattering and recoil corrections are discussed in the next section. 


\section{III - Formalism and data analysis}

The coherent scattering cross section of neutrons by an assembly of fixed nuclei (forming molecules or not) is written as $/ 2 /$

$$
\left(\frac{d \sigma}{d \Omega}\right)_{\infty h}=\frac{k}{k_{0}}\left\langle\left|\sum_{j} \vec{b}_{j} \exp \left(i Q \cdot r_{j}\right)\right|^{2}\right\rangle
$$

where $\bar{b}_{j}$ is the scattering length, and the summation being performed over all nuclei in the system

$\mathrm{k}_{0}$ and $\mathrm{k}$ are the momentum of the neutron before and after scattering, respectively.

$r_{j}=r_{n}+u_{n}+r_{n a} \quad\left(r_{n}\right.$ is the equilibrium position of the centre of mass

$\mathbf{u}_{\mathbf{n}}$ is a displacement of the centre of mass

$\mathbf{r}_{\mathrm{na}}$ is the position of the atom a in relation to the centre of mass of the same molecule $n$ )

For a molecular crystal the rotational structure factor in the direction $\Omega_{\mathrm{n}}$ is written

$$
F\left(\Omega_{N}\right)=\sum_{a}\left[\vec{b}_{a} \exp \left(-i \vec{Q} \cdot \vec{r}_{n a}\right)\right]
$$

where $\vec{r}_{n a}$ is the position of the atom a with respect to the centre of mass $n$ of the same molecule If local corriations between neighbor complex molecules are ignored, the total coherent cross section for $\mathrm{N}$ identical molecules, including intramolecular correlations may be written as

$$
\frac{d \sigma}{d \Omega}=\frac{k}{k_{0}}\left\{\sum_{n n^{\prime}}|\langle F\rangle|^{2} e^{-i \vec{Q} \cdot\left\{r_{n}-r_{n}\right\}} e^{-2 W}+N\left[\langle\Delta F)^{2}+|\langle F\rangle|^{2}\left(1-e^{-2 W}\right)\right]\right\}
$$

where the first term takes into account the Bragg scattering

$\mathrm{W}$ is the Debye-Waller factor and

$$
(\Delta \mathrm{F})^{2}=\sum_{\mathrm{a}^{\prime}} \mathrm{b}_{\mathrm{a}^{\prime}} \mathrm{b}_{\mathrm{a}^{\prime}}\left\{\left\langle\exp \left(\mathrm{i} \overrightarrow{\mathrm{Q}} \cdot \overrightarrow{\mathrm{r}}_{\mathrm{a}^{\prime}}\right)\right\rangle-\left\langle\exp \left(-\mathrm{i} \overrightarrow{\mathrm{Q}} \cdot \overrightarrow{\mathrm{r}}_{\mathrm{a}}\right)\right\rangle\left\langle\exp \left(\mathrm{i} \overrightarrow{\mathrm{Q}} \cdot \overrightarrow{\mathrm{r}}_{\mathrm{a}^{\prime}}\right)\right\rangle+\text { incoherent }\right\}
$$

is the diffuse scattering for one compound molecule.

In molecular crystals, there are generally no more Bragg peaks visible at momentum transfers $Q$ larger than $10 \AA^{-1}$. Only intramolecular correlations of small molecules contribute to the diffraction pattern in the 
large Q-range. In this case equation 3 reduces to

$$
\left(\frac{d \sigma}{d \Omega}\right)_{C o h}=\sum_{a a^{\prime}}^{m}\left[b_{a} b_{a^{\prime}} \cdot \frac{\sin \left(Q r_{2 a^{2}}\right)}{Q r_{2 a^{2}}} \exp \left(\frac{-\left\langle\Delta r_{2 a^{2}}^{2}\right\rangle Q^{2}}{2}\right)\right]+\text { incoherent }
$$

the sum is extended to all the pairs of the $m$ atoms forming the small molecule; an additional Debye-Waller factor taking into account intramolecular vibrations has been introduced.

Several corrections must be performed on the raw data before determining the molecular parameters from a fit using equation 5 . The details of the correction procedure have been given elsewhere $/ 1 /$; only the general features are reported here:

Inelastic correction. The measured differential cross section is actually the sum of a self and a distinct contribution; the self term is made of the incoherent scattering and the coherent autocorrelation contribution. Placzeck $/ 3$ / has shown that inelastic corrections must be performed on the self part and may be developed as a series expansion as a function of $Q^{2}, Q^{4}, Q^{6} \ldots$

Multiple-scattering effect. The evaluation of multiple scattering may be made using the method of Blech and Averbach /4/ for cylinders. Egelstaff /5/ showed that, with such a sample geometry, the correction did not depend on the angle for $Q$ larger than $6 \AA^{-1}$. Thus, in the large angle range that is investigated here, this correction has been entered as a constant.

Recoil correction. For light atoms (or molecules), the distinct term must be corrected for recoil if the atoms (or molecules) are allowed to move more or less freely. The correction depends on the ratio $\mathrm{M} / \mathrm{m}_{\mathrm{n}}$, where $M$ is the atomic mass and $m_{n}$ is the neutron mass. For a rigid crystal, $M / m_{n}$ goes to infinity. In a plastic crystal, $M$ is an effective mass since the molecules are neither free to move nor tightly bonded to the lattice; this unknown effective mass must thus be determined from the fit.

The complete equation used in the fitting procedure, including corrections, is then written as

$$
\begin{aligned}
& \left(\frac{d \sigma}{d \Omega}\right)_{\text {tot }}=A_{0}\left(1+A_{1} Q^{2}+A_{2} Q^{4}+A_{3} Q^{6}\right)+B \sum_{i \neq j}^{m}\left[b_{j} b_{j} \frac{\sin \left(Q_{\text {eff }} r_{i j}\right)}{Q_{\text {eff }} r_{i j}} \exp \left(\frac{-\left\langle\Delta r_{i j}^{2}\right\rangle Q_{\text {eff }}^{2}}{2}\right)\right] \\
& \text { where } \quad Q_{\text {eff }}=Q\left[1-\frac{m_{n}}{M}\left(\frac{\lambda}{4 \pi}\right)^{2} Q^{2}\right]
\end{aligned}
$$

There are two distances $\mathrm{r}_{\mathrm{ND}}$ and $\mathrm{r}_{\mathrm{DD}}$ in the $\mathrm{ND}_{3}$ group; thus 10 parameters were allowed to vary in fits using equation 6. 


\section{IV - Results and discussion.}

The scattering pattem obtained for the lithiumtetraammine compound at $4 \mathrm{~K}$ is reported in figure 1 .

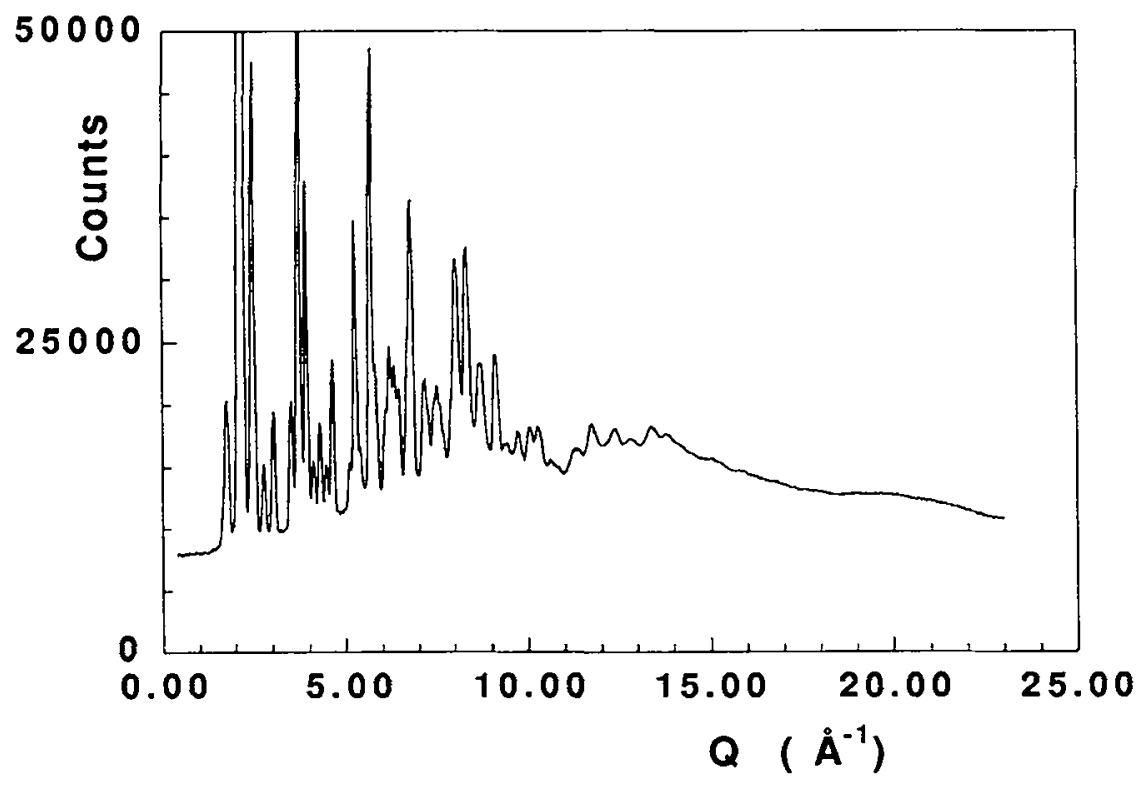

FIG 1. Diffraction pattern for the lithiumtetraammine compound at $4 \mathrm{~K}$. The damped oscillations observed in the large $Q$-range $\left(Q>12 a^{-1}\right)$ are due to the intramolecular correlation of the $N_{3}$ group only.

Only data points recorded in the $12-23 \AA^{-1}$ Q-range were used in the fit. Several small Bragg peaks remaining for $Q$ larger than $12 \AA^{-1}$ were removed by filtering. The best results obtained from 360 data points are

$$
\begin{aligned}
& \mathrm{r}_{\mathrm{ND}}=1.016(4) \quad \text { with } \Delta \mathrm{r}_{\mathrm{ND}}^{2}=4.1 \times 10^{-3} \\
& \mathrm{r}_{\mathrm{DD}}=1.596(9) \quad \text { with } \Delta \mathrm{r}_{\mathrm{DD}}^{2}=9.5 \times 10^{-3} \\
& \mathrm{M}=29 \text { a.u. and } \widehat{\mathrm{D}-\mathrm{N}-\mathrm{D}}=103.5 \text { degrees }
\end{aligned}
$$


To the nearest $10^{-2} \AA$, the molecular parameter of the $\mathrm{ND}_{3}$ group in the lithium-ammonia compound are the same as that found in solid or liquid $\mathrm{ND}_{3}$ and in the calcium-hexaammine compound /1/. The residue has almost exactly the value expected from the statistic uncertainty. The effective mass found from the recoil correction shows that the ammonia is not tightly bonded to the metal ion (a mass of 34 a.u. was found for the $\mathrm{Ca}(\mathrm{ND})_{3}$ compound).

The interference molecular function is reported in figure 2.

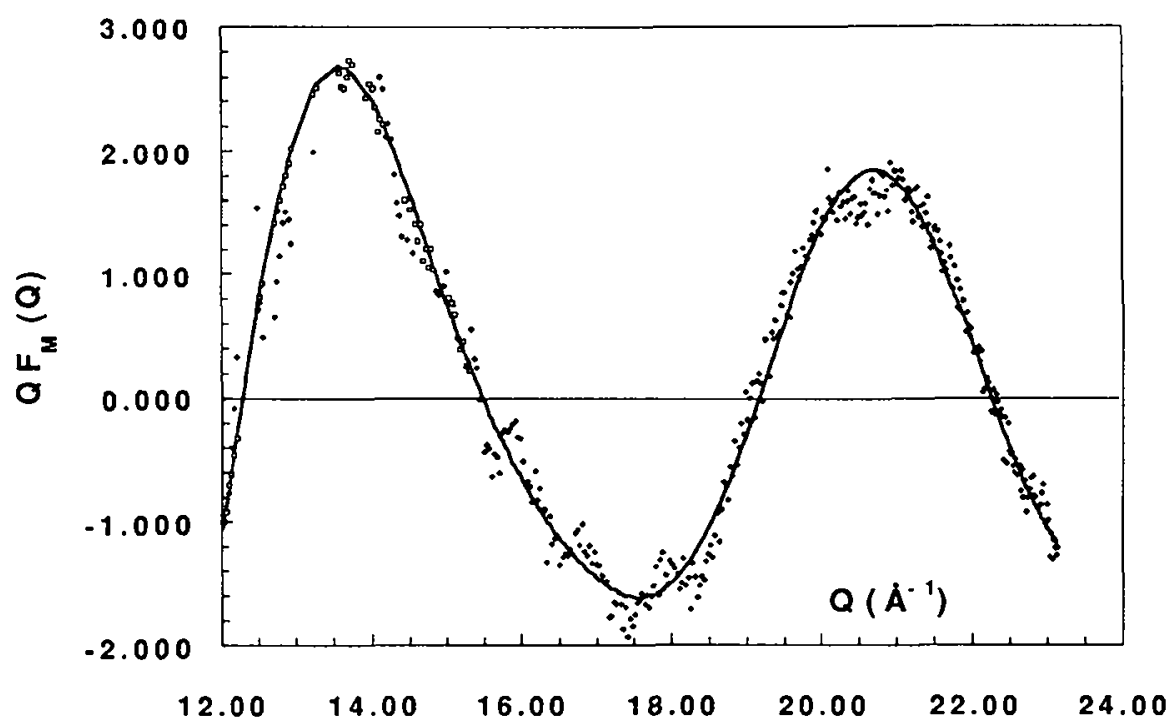

Fig 2. The interference function of the $\mathrm{ND}_{3}$ group in the lithium-tetraammine compound. Remaining traces of Bragg peaks have been removed by filtering in the $12-14 \AA^{-1}$ region.

The same parameters were found when varying fitting conditions, for example changing the low-Q cutoff from 12 to $15 \AA^{-1}$, keeping only 2 inelastic parameters and so on. Furthermore the fit did resist any tentative to distort the geometry of the molecule; as an example the residue increased by an order of magnitude if one of the nitrogen-deuterium distance was held constant $\left(\mathrm{r}_{\mathrm{ND}}=1.04 \AA\right.$ instead of $1.015 \AA$ ) and allowing two different DD distances. 
As a conclusion, we showed that Large Angle Neutron Scattering is a powerful technique to study small rigid molecules in condensed phases, specially in highly disordered crystals as the metal-ammonia compounds. It is then possible to use these molecular parameters as constants in the refinement of the structure from Bragg peaks intensities, thus reducing the number of free parameters.

\section{Bibliography.}

1/ DAMAY P., LECLERCQ F., CHIEUX P., Phys.Rev. B 41, 9676 (1990).

121 LOVESEY S.W., Theory of neutron scattering from condensed matter, volume 1, Oxford University Press, New-York - (1984)

13/ PLACZEK G., Phys.Rev., 86, 377 (1952)

14/ BLECH I.A., AVERBACH B.L., Phys.Rev. 117, 1113 (1964)

15/ EGELSTAFF P.A., in “ Methods of Experimental Physics - vol. 23, part B -

Neutron Scattering “, Academic Press, New-York, 1987 page 405 